\title{
Overcoming Poverty in Multidimensional Poverty Interventions through Self-assessment and Mentoring
}

\author{
Juan Pane ${ }^{1}$ \\ Katharina Hammler ${ }^{2}$ \\ University of Sussex
}

\section{Scientific Article}

Original material authorized for its first publication in the Journal de Ciencias Sociales, the Academic Journal of the Social Sciences School of Universidad de Palermo.

Reception: 31-08-2019

Approval: $06-10-2020$

\begin{abstract}
A microfinance organization in Paraguay has developed the "Poverty Stoplight" (PS), an innovative technological tool that allows families to self-assess their level of multidimensional poverty and start an integrated mentoring process whose goal is to empower families to eliminate multidimensional poverty based on what the participants value the most. During the program, a mentor works with participants to design a customized family plan to identify their most significant challenges in order to overcome their deprivations. The PS places human development and poverty elimination as the main objectives for the intervention. This paper has three elements. First, it presents the methodology for poverty intervention and the detailed tool (i.e. a multidimensional metric) used to encourage reflecting and promoting agency. Second, it uses the Capability Approach to explore the potential of the PS intervention to increase agency and decrease multidimensional deprivations. Third, it presents results from an ongoing research project that evaluates the program's effectiveness in helping participants overcome poverty. This empirical part is based on data collected between August 2015 and June 2017 from over 9,000 microfinance clients and analyzed using the technique of OLS regressions. The results indicate that participation in the program is indeed associated with a higher probability of overcoming multidimensional poverty.
\end{abstract}

\footnotetext{
${ }^{1} \mathrm{He}$ is a doctoral researcher at the Institute of Development Studies (IDS) at the University of Sussex. His research interests include power and empowerment, poverty, and international development. He has a Master's degree in Political Science from the University of Missouri (USA) and a Master's degree in Social Research from the University of Edinburgh (UK). He has extensive working experience as a development practitioner.

Correo electrónico: juanp@ids.ac.uk

2 She is the Director of Monitoring and Evaluation (M\&E) of Fundación Paraguaya. She was born in Austria where she studied Economics, Socioeconomics, and Political Sciences before earning a Ph.D. in Global Development from Tulane University in New Orleans, USA. She has worked as a consultant in several education development projects and taught poverty measurement at the University of Vienna.

Correo electrónico: khammler@fundacionparaguaya.org.py
} 
Keywords: empowerment, multidimensional poverty, self-assessment, mentoring.

\section{Superando la Pobreza con Intervenciones Multidimensionales a través del Auto-diagnóstico y la Mentoría}

Resumen: Una organización de microfinanzas en Paraguay ha desarrollado el "Semáforo de Eliminación de Pobreza" (PS), una herramienta tecnológica innovadora que permite a las familias autoevaluar su nivel de pobreza multidimensional y comenzar un proceso de tutoría integrado que tiene el objetivo de empoderar a las familias para eliminar la pobreza multidimensional en función de lo que los participantes valoran más. Durante el programa, un mentor trabaja con los participantes para diseñar un plan familiar personalizado para identificar sus desafíos más importantes para superar sus privaciones. El PS coloca el desarrollo humano y la eliminación de la pobreza como el objetivo principal de la intervención. Este artículo tiene tres objetivos. Primero, presenta la herramienta como una métrica multidimensional y una metodología para la intervención de la pobreza con el propósito explícito de fomentar la reflexión y promover la agencia. En segundo lugar, usa el Enfoque de Capacidad para explorar el potencial de la intervención del PS para aumentar la agencia y disminuir la privación. En tercer lugar, presenta los resultados de un proyecto de investigación en curso que evalúa la efectividad del programa para ayudar a los participantes a superar la pobreza. Esta parte empírica se basa en datos recopilados entre agosto de 2015 y junio de 2017 de más de 9,000 clientes de micro finanzas y analizados mediante regresiones OLS. Los resultados indican que la participación en el programa está asociada con una mayor probabilidad de superar la pobreza multidimensional.

Palabras clave: empoderamiento, pobreza multidimensional, auto-evaluación, mentoría.

\section{Introduction}

Fundación Paraguaya (FP), a Paraguayan microfinance organization, claims to have developed an innovative poverty intervention that empowers people to overcome the issues of poverty through the process of self-assessment and mentoring. The PS is a self-diagnostic visual survey that provides information intended to assist families in assessing their level of poverty as Red (extreme poverty), Yellow (poverty), or Green (non-poverty) across 50 indicators. The survey is embedded into a mentoring program. The process is executed with the help of mentors, who specifically, help participants understand each indicator, and together they discuss which color best represents the situation of the family. Then, using the information gathered from the survey, the staff works with participants to design a customized family plan to address the areas identified as the most significant challenges. 


\subsection{Problem statement}

This paper analyses whether participating in a multidimensional poverty selfassessment and mentoring intervention has the potential to increase participants' agency and thus reduce their multidimensional poverty.

The findings of this ongoing research project is relevant for practitioners, policymakers, academics, and the social science community in general because the empirical knowledge base on interventions focused on empowerment and agency through mentoring remains limited, despite some promising results (for instance: Beaman et al. 2012; Bernard et al. 2014; Hart, 2016; Ibrahim, 2011; Janzen et al. 2017; Lybbert \& Wydick, 2017; Macours \& Vakis, 2009). More specifically, there is a lack of knowledge on whether the approach taken by the PS helps people overcome poverty. Our final hope is to clarify and advance knowledge for poverty elimination in development practice.

Throughout this paper, the Capability Approach (CA) is used as the theoretical framework to analyze and understand the PS and its claims for the empowerment of those experiencing poverty. The CA is in essence a people-centered approach to assess individual well-being and social arrangements. The CA is well suited as a firm theoretical framework for the PS, since the PS places human development as the main objective of the intervention. The PS intervention defines people as agents who can reflect, aspire, and take actions to change their lives according to what they value and care about.

The remainder of this paper is structured as follows. The remainder of section 1 presents the PS intervention in detail. Section 2 introduces the CA as the theoretical framework of this program. In section 3 , this paper will present some of the available empirical evidence. After presenting methods and data for our own study in sections 4, sections 5 and 6 present the results that indicate that the PS seems to help participants decrease their deprivations. Finally, section 7 provides a conclusion to the paper.

\subsection{The Poverty Stoplight Program}

According Fundación Paraguaya (2018a), the Poverty Stoplight (PS) is "a metric and, at the same time, a methodology that allows families to measure their level of [multidimensional] poverty as well as identify and create customized strategies to solve their specific deprivations". The PS program was conceived in 2010, initially to guide the field work with FP's microfinance clients, whereas it is now used in a variety of contexts by over 300 organizations in 30 countries around the world (Burt, 2019).

A defining characteristic of the PS is that it was developed with the purpose to include the most important but usually neglected stakeholders. Thus, the primary users of the data 
produced by the PS were to be the very participants assessing their poverty (Burt, 2013, 2019). This is a fundamental departure from conventional surveys, which collect information from families to be analyzed and used by different people or entities. The PS metric and mentoring program are closely intertwined and designed to provide the information and support that is necessary for people who live in poverty to diagnose their situation and overcome their deprivations. These two aspects of this poverty elimination program will be presented separately in the following subsections.

\subsubsection{The Poverty Stoplight metric}

The Poverty Stoplight consists of 50 multidimensional indicators that are grouped into six dimensions: Income \& Employment, Health \& Environment, Housing \& Infrastructure, Education \& Culture, Organization \& Participation and Interiority \& Motivation. Each of the 50 indicators is defined in the three levels Green (representing no deprivation), Yellow (moderate deprivation), and Red (extreme deprivation). The indicators were developed in collaboration with local stakeholders such as people experiencing poverty and experts on poverty issues through different processes such as focus groups and individual interviews.

The indicator level descriptions are accompanied by illustrations that help illiterate respondents to identify the most accurate answer option. The illustrations are also meant to give a visual representation of a life out of poverty, which is meant to start a process of reflection about one's situation, and eventually contribute to an increase in aspirations. Figure 1 gives an example for a PS indicator. 


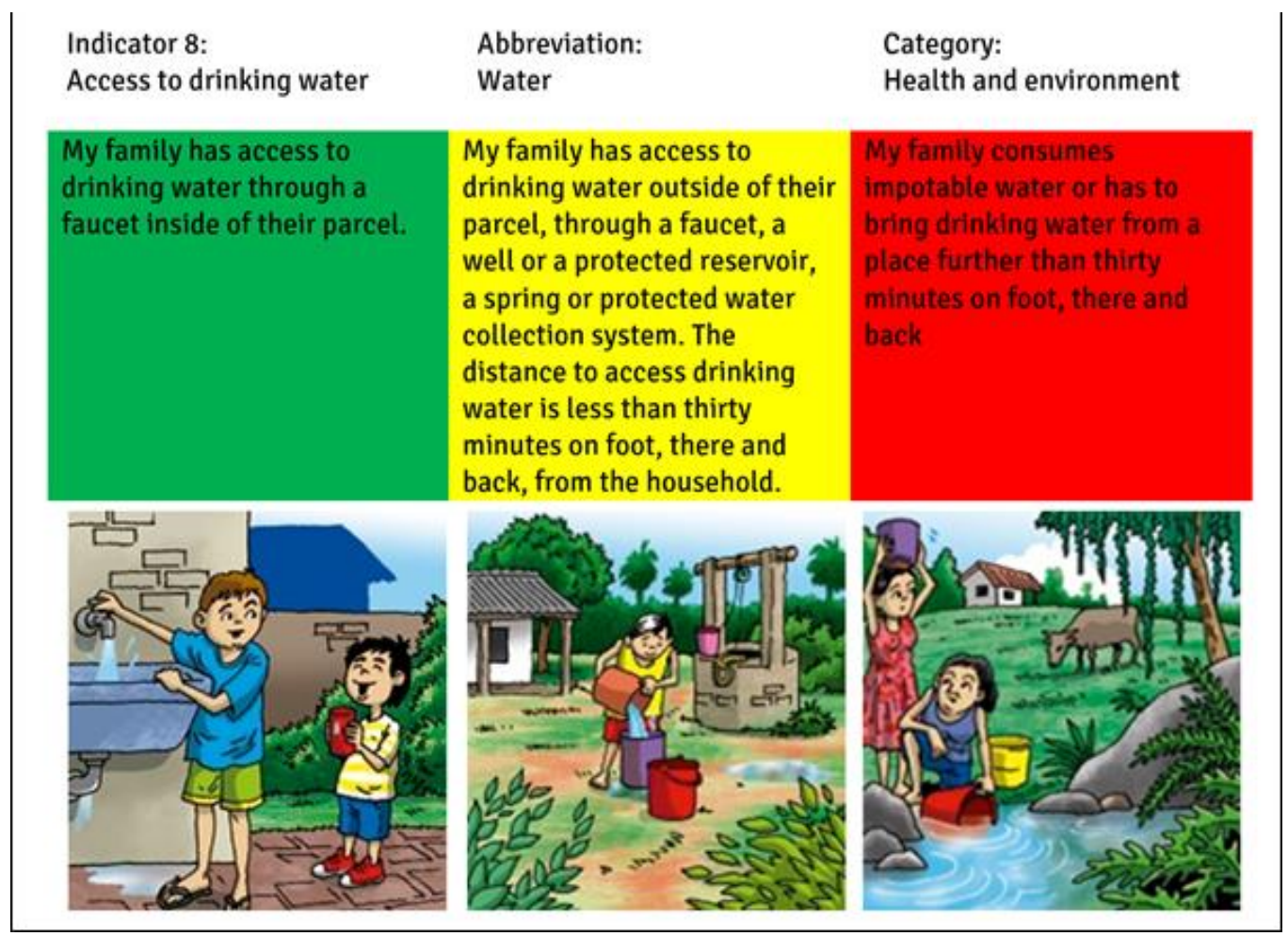

Figure 1. Example of a Poverty Stoplight indicator (Fundación Paraguaya, 2018b)

The survey is done through a digital platform that can be used online or via an App. A PS mentor guides the participant through the questions, and clarifies concepts or probes answers where necessary - but importantly, it is the respondent who in the end chooses which of the three levels best reflects her reality, and who actively picks the respective option by touching the screen (Burt, 2013; Fundación Paraguaya, 2014).

Immediately after the survey is completed, the software presents the participant's poverty dashboard that summarizes the Greens, Yellows, and Reds. The PS defines those living in poverty as the main stakeholders of their data, and as the most important decision makers when it comes to eliminate their poverty. As such, they need dis-aggregated data that allows them to analyze the possibly overwhelming problem of their own poverty in a granular way, taking stock of both the resources that are already available in the family (the Greens), and the areas of moderate and extreme deprivations (Yellows and Reds). For other stakeholders, such as the implementing organization, the PS provides options of aggregating the data - from simple metrics such as the percentage of Reds and Yellows in a given indicator in a community, to more technically advanced metrics, such as an Alkire/Foster-type Multidimensional Poverty Index (Alkire \& Foster, 2011). 


\subsubsection{The Poverty Stoplight methodology: self-assessment and mentoring}

The mentoring methodology starts during the surveying process and builds directly upon the poverty dashboard. As all 50 multidimensional indicators are designed to be achievable, according to the PS program theory the presentation of a Green in the surveying stage already serves as a first demonstration that a situation of "non-poverty" can be attained by the participant. During the self-diagnosis, participants are supported by FP mentors through a dialogue with the aim of identifying where they are and where they could be. After the selfassessment, the participant, together with the PS mentor, starts elaborating what has been identified as a 'life map': Out of all her Yellows and Reds, she picks five priority areas in which she wants to improve first. These are tagged in the Software and at the same time written into a cardboard map that will stay with the participant. The participant, together with the PS mentor, then reflects on the potential causes of the deprivations and formulates concrete steps that she will take to overcome them.

While FP provides some problem solutions (for instance, if a lack of funding is identified as a roadblock, a family might receive a loan), the overall goal is to mobilize all resources that are available - at the level of the family, from neighbors, in the municipality or from state or national government agencies, for instance. All solutions are registered in the PS platform and build an ever-increasing solutions database that participants and mentors can consult.

After a given time-typically after around half a year to a year, with variations among different program adaptations-participants do a follow-up PS survey. Together with their mentor, they reassess their deprivations in all indicators and use that information to reflect on their progress, and to choose their next improvement priorities. These follow-up surveys also provide valuable information for the implementing organization, as the data can be analyzed in conjunction with the attempted solutions that were registered in the platform.

\section{State of the Art: Overcoming poverty through aspiration- mentoring}

There is some evidence that the PS program helps families overcome poverty. Apart from anecdotal evidence brought forward by FP, there are two quantitative studies that are based on administrative data from FP clients who were purposefully selected to participate in the program (Budzyna \& Magnoni, 2013; Burt, 2014). Both conclude that program participation is associated with a decrease in deprivations, but the data does not allow to assume any causal relationship. It is possible to look at the wider literature, however, to understand whether a program that focuses on expanding people's capabilities through aspirationincreasing mentoring may have positive effects. 
A growing body of literature suggests that increasing people's aspirations can help them overcome poverty. Based on the theoretical work on aspirations, empirical researchers have gathered evidence on the social formation of aspirations, and that they do indeed matter in practice. An often-cited example is a study from India (Beaman et al., 2012) that shows that in villages that were randomly selected to have a female leader, the gender gap in aspirations narrowed considerably, and the gender gap in adolescent educational attainment was completely closed. The authors attribute these changes to increased aspirations of the girls. Bernard et al. (2014) show that much less is required to raise aspirations and see real changes. They analyze how the screening of short motivational documentaries to rural populations in Ethiopia influences aspirations and outcomes such as educational spending and hours worked. A similar project in Mexico had comparable effects (Lybbert \& Wydick, 2017): Women microfinance clients who were shown an inspirational documentary and then participated in weekly discussions about hope, agency, and related topics showed increased aspirations.

In recent years, poverty mentoring has gained importance (Sheldon, 2017). This is a promising development, given that research has shown that a good mentoring relationships can lead to higher levels of positive motivation and social-emotional and cognitive resources (Eby et al. 2008; Fletcher \& Ragins, 2007; Rhodes \& DuBois, 2008). Directly in the context of poverty elimination, researchers have found highly promising results regarding the potential benefits of mentoring, for instance in evaluating BRAC's Graduation Approach (Bandiera et al. 2017; Banerjee et al, 2015; Banerjee et al. 2018). However, the evidence base is still rather small, and more research is needed to better understand the mechanisms and effects.

Put together, the literature suggests that aspirations and mentoring are promising tools in the pathway out of poverty. However, our understanding on how these processes work, and what types of interventions can be successful, is still limited.

\section{Theoretical Perspective}

The Capability Approach (CA) is, in essence, a people-centered approach for development. It is a normative framework to evaluate individual well-being and social arrangements (Clark, 2005; Robeyns, 2017; Sen, 1999). The CA is "focused on what people can do and be (their capabilities) and on what they are actually achieving in terms of beings and doings (their functionings)" (Robeyns, 2017, p. 36). The CA is multidisciplinary, mostly applied in development studies, social policy, and welfare economics, and defines and conceptualizes notions such as poverty, inequality, and well-being (Alkire, 2005; Sen, 1999). Sen (2009, p. 16) defines the CA as "an intellectual discipline that gives an essential role to 
the evaluation of a person's achievements and freedoms in terms of his or her actual ability to do different things a person has reason to value doing and being".

This paper uses the CA as a theoretical framework for various reasons. First, the CA allows us to put the individual at the center of our research. Second, the CA does not limit its informational basis by focusing exclusively on utilities, happiness or rights and this helps us to cover the individual as a whole considering, for example, people's interpersonal differences, context, and aspirations (Robeyns, 2003). Third, the CA allows us to assess the effects of the PS in terms of achieved wellbeing and wellbeing freedoms (Sen, 2009).

There is a distinction between the term Capability Approach, referring to the general, open, and underspecified framework, and the term Capability Application, referring to a specific use of the Capability Approach (Robeyns, 2017). In this section, the paper will refer to the Capability Approach (or CA) by briefly presenting its main concepts. In the next section it will introduce the specific use of the CA for the PS intervention, that is, our Capability Application.

\subsection{The Main Components of the Capabilities Approach}

The CA in its more general sense is based on eight core concepts that Robeyns (2017) calls "A-modules". The first of these A-modules are functionings and capabilities. Functionings are things that a person actually manages to do or be, in contrast to capabilities that are about what is possible to achieve depending on the freedoms or valuable options from which the person can choose (Nussbaum, 2000; Sen, 1999). A central part of Sen's definition of functionings is the concept of 'value and have reason to value'. According to this, an activity or situation 'counts' as a valuable functioning for that person only if that person values it (Sen, 2009). This encourages the participation and engagement of those people whose lives are at stake. Functionings are related to different dimensions of life such as health, education, relationships, culture and so forth (Alkire \& Deneulin, 2009). Capabilities are a person's freedom to achieve various functionings. This is the set of choices that are open to the person (Alkire \& Deneulin, 2009; Sen, 1992, 1999).

The second core module of the CA states that functionings and capabilities are valueneutral categories: they can have positive, negative or neutral values (Robeyns, 2017). The third module is that individuals have different abilities to convert resources into functionings, which are called conversion factors (Robeyns, 2017). The idea is to understand how much functioning the individual can get from a specific resource. A bicycle (as a resource) may provide the functioning of mobility; however, different levels of conversion factors arise depending on the person's ability to transform the resource into functioning (such as having 
learnt to ride a bike). The fourth central module of the CA is the distinction between means and ends. This distinction requires the researchers to evaluate whether it values something as an end or as a mean to an end. For example, being healthy could be an end whereas the means necessary for this end are clean water, access to doctors, and so forth (Robeyns, 2017).

The fifth key module is the use of functionings and/or capabilities as the evaluative space, i.e., the space where interpersonal comparisons and personal evaluations can be made to evaluate the wellbeing of people (Robeyns, 2017). The sixth module concerns the dimensions of ultimate value different from functionings and/or capabilities. Sen (2004) argues that the CA does not capture the procedural aspect of freedom but only the opportunity aspect of it, hence it needs to be complemented with other dimensions such as fair process. The seventh key module is related to the value of pluralism within the CA. Pluralism in the sense that users of the CA should accept other dimensions of ultimate value as mentioned in the sixth concept as well as the multidimensional nature of the CA (Sen, 2004). Finally, the eighth module is related to what Nussbaum (2000) called 'the principle of each person as an end'. This concept implies that any policy intervention, program, or analysis should look at every individual as an end, and neither look only at the average individual, nor treat individuals as pure means to reach aims defined at the level of the group or society.

\subsection{The Poverty Stoplight and the Capability Approach}

This section introduces the PS as a Capability Application. In addition to the A-modules outlined above, Robeyns (2017) proposes that applications of the CA need to show how they respond to a range of basic characteristics (or $B$-modules). This section attempts to showcase the alignment mentioned.

The purpose of the PS is twofold; On the one hand, the PS is an attempt to measure multidimensional poverty, providing data on deprivations that is useful for those carrying out the measurement (generally, families living in poverty), but also for other stakeholders, such as NGOs or even government agencies. Hence, as a measurement tool the PS aims to meet the needs of a wide field of audiences. On the other hand, as a self-diagnosis survey and mentoring methodology the PS also aims to help participants to reflect on their own situation, increase their aspirations and enhance their agency, thus increasing their capabilities. It is important to note that the CA was not the starting point for designing the PS program; rather, this paper aims to ex-post embed the PS into the CA, arguing that the PS can be understood as one Capability Application. 


\subsection{The PS metric and the CA}

The indicators of the PS were developed based on a broad review of the literature on multidimensional poverty measurement, on expert consultations, and on focus groups with the communities in which the tool is being used. This three-part process generated a set of 50 indicators that cover a wide range of topics, including conventional topics like health and education, but also some more unconventional topics such as having a high self-esteem or having regular recreational activities.

Overall, the selection and definition of indicators can best be described as a combination of a bottom-up process and expert consultations. However, the intention of the PS is to present a list of poverty indicators that are relatable to survey-takers so that the process of self-assessing one's level of poverty encourages reflection and thereby beginning a shift in aspirations. Hence, the question arises whether it introduces noise if external experts add indicators or make changes to the list generated in the bottom-up process? Both from FP's viewpoint, and from the perspective of the CA, the answer is 'no'. FP explains that 'it is not only possible but advisable to simultaneously consider multiple viewpoints and perspectives inherent in any debate" (Burt, 2013, p. 54), and defines itself as the "mapmaker" who draws a poverty map based on the inputs from those experiencing poverty. From the perspective of the $\mathrm{CA}$, including the perspective of outsiders makes sense because of the phenomenon of adaptive preferences:

A group that is systematically socialized to have low aspirations and ambitions will perhaps not put certain capabilities on its list [of important dimensions], thereby telling themselves that they are unachievable, whereas objectively speaking they are achievable, albeit perhaps only after some social changes have taken place (Robeyns, 2017, p. 139).

The levels of each indicator of the PS were intended to be defined so they can be reached if a family shows a certain behavior or achieves a certain state (Burt, 2013). As a result, the evaluative spaces are mostly functionings or sometimes capabilities. There are also a few indicators that remain on the level of resources. These resources typically have high instrumental value, or a wide range of capabilities or functionings can be associated with them. In a recent round of revisions, PS indicators were adjusted to be aligned with existing multidimensional poverty metrics that are explicitly based on the framework of the CA: The Global Multidimensional Poverty Index or Global MPI (Alkire \& Santos, 2010) as well as the proposed Paraguayan MPI (Ervin et al. 2017). 


\subsection{The PS self-assessment and mentoring methodology and the CA}

While the PS as a metric operationalizes the way the CA might describe multidimensional poverty, the PS methodology operationalizes the way that the CA might see a pathway out of poverty. And just as for the former, the latter component of the PS was not explicitly developed based on the CA, but can in its claims and strategies be understood and evaluated in this framework, as the following discussion will show.

\subsubsection{Self-assessment and Reflection}

Borrowing from the way Freire (1970) characterizes traditional education, many conventional poverty interventions can be described as treating people like empty repositories that the government or other institutions have to fill with skills, assets, and other resources. In order to decide on the type of intervention to carry out or to evaluate program outcomes, conventional programs extract information from those experiencing poverty using traditional surveys. This process does not allow dialogue and reflection because the individual is subjected to the simple role of data surveyor; the process does not recognize the role of reflection as a step to overcome poverty. One of the innovations the PS introduces to poverty programs is that participants self-diagnose their level of poverty creating a self-reflection process.

The Poverty Stoplight helps families reflect on and analyze their current situation as a step to recognize deprivations and take actions to overcome them. The concept of 'reflection' used by the PS is related to what Freire called 'conscientisation'. In fact, this paper uses the term conscientisation as a synonym of reflection. Conscientisation represents "the development of the awakening of critical awareness" (Freire, 1973). Freire proposed that to reach 'conscientisation' an external intervention is necessary, in which individuals experiencing poverty have participatory consultations to develop a dialogue with the objective of awakening critical thinking and analyzing their situation, thus learning and reflecting from that experience. During the process of dialogue, the individual gradually will gain her ability to choose and more importantly to "become responsible for her own development and to act towards addressing the constraining social structures that oppress her and others around her" (Poveda, 2015, p. 33).

The poverty measurement process employed by the PS is designed to start this process of reflection. People experiencing poverty are no longer docile recipients of poverty programs but ready to critically engage and co-produce knowledge and actions in dialogue with a mentor. Through the self-diagnosis survey, the PS provides participants an opportunity to reflect, question, and assess their own deprived situation as a prerequisite to act upon this 
to improve their lives. By introducing reflection as a required step for individuals who participate in the PS, the CA is inherently being introduced.

\subsubsection{Agency to overcome poverty}

All 50 indicators of the PS are designed to be actionable and achievable by participants. This means that the active involvement and action of participants of the PS make them agents of change of their own lives. An agent is "someone who acts and brings about change, and whose achievements can be judged in terms of her own values and objectives, whether or not we assess them in terms of some external criteria as well" (Deneulin \& Shahani, 2009 , p. 31). Concerns for people's agency and empowerment play a key role in the CA since "greater freedom enhances the ability of people to help themselves, and also to influence the world, and these matters are central to the process of development" (Sen, 1999, p. 152).

Agency and empowerment, like poverty, are plural concepts as well as measurements. They are sometimes treated as synonymous, although in a strict sense they are related but different in their definitions (Ibrahim \& Alkire, 2007; Kabeer, 1999; Narayan, 2005). Agency is about the ability of an individual to make choices about her goals and take action to achieve them; empowerment is the expansion of agency (Ibrahim \& Alkire, 2007; Kabeer, 1999; Narayan, 2005). Empowerment is considered the expansion of agency because it is comprised by a) agency and b) the institutional environment, as a pre-condition for agency, which allows individuals to exercise agency (Alsop et al. 2006; Ibrahim \& Alkire, 2007; Narayan, 2005). These two elements are not considered mutually exclusive and the process from disempowered to empowered could be considered incomplete unless they are both present.

Additionally, beliefs of personal efficacy constitute the key factor of human agency. If people believe they have no power to produce results, they will not attempt to make things happen (Bandura, 1997). However, people have the power and motivation to change their situation (Chambers, 1997; Narayan, 2005; Sen, 1999). This is why "an empowering approach to poverty reduction is grounded in the conviction that poor people themselves are invaluable partners for development, since they are the most motivated to move out of poverty" (Narayan, 2005, p. 3).

\subsubsection{Frame of reference/adaptive preferences}

Adaptive preference refers to the negative impact that adjusting to negative circumstances may cause to the individual's freedom (Nussbaum, 2000; Sen, 1999). The CA has been concerned with the existence of adaptive preferences from the beginning. For 
instance, the CA's rejection of a utilitarian approach to welfare measurement is partly based in the realization that "[o]ur desires and pleasure-taking abilities adjust to circumstances, especially to make life bearable in adverse situations. The utility calculus can be deeply unfair to those who are persistently deprived" (Sen, 1999, p. 62). Due to the existence of such adaptive preferences, people who suffer from deprivations might actually report a level of wellbeing that is higher than what they would report were they not suffering from such deprivations.

\section{Increasing aspirations, increasing capabilities}

The value of the PS intervention for people experiencing poverty lies in its ability to induce them to connect themselves to a world out of their situation of deprivation (to "become Green"). Through a self-diagnosis and dialogue with a mentor, the individual will acquire a new vision that will allow them to free themselves from what Freire (1973) defined as the state of oppression.

Aspirations are hopes or ambitions to achieve something in life (Ibrahim, 2011). Appadurai (2004, p. 59) indicates that "in strengthening the capacity to aspire [...] the poor could find the resources required to contest and alter the conditions of their own poverty". The way individuals understand the world and how they select their preferences and aspirations for the future is a socially constructed process. Only when individuals consider their own capacity to aspire, do these processes and constraining cultural norms become addressed and revealed. For example, Conradie and Robeyns (2013, p. 565) argue:

Thinking about, talking about, and reflecting upon aspirations, especially when this is part of a group process that creates a supportive and encouraging atmosphere, motivates people to use their latent agency to make changes in their lives, which will expand their capabilities.

To achieve their aspirations, individuals experiencing poverty have to exercise their voice and their human agency (Appadurai, 2004), and having these aspirations is crucial in order to work towards a positive change. Conversely, not having "adequate" aspirations may inhibit people from achieving a life they would value: As first argued by Ray (2006), and later formalized by Genicot and Ray $(2011,2017)$ and Dalton et al. (2016), people can get stuck in poverty due to aspiration failures, that is, due to their aspirations not being ambitious enough, or due to the feeling that there is just no way to achieve them. As aspirations are formed in the social context in which a person lives, a poor individual is likely to adjust her aspirations to what others have achieved who live in a similar situation as herself. This might well mean that a life out of poverty seems unachievable and is thus not aspired to. Hart $(2012 ; 2016)$ 
embeds the concept of aspirations into the Capabilities Approach, showing that aspirations are an important step in the realization of many functionings.

The PS addresses this situation, starting with the measurement process: For each indicator, the level Green is presented as an achievable situation of non-deprivation. Thus, Green is not an abstract answer category among others but helps families to imagine themselves as not deprived. Hence, already in the measurement phase, families are encouraged to rethink what they see as possible and start adjusting their aspirations.

Defining priorities: improve on what you value and have reason to value

One of the important contributions of the CA is the focus on the things that a person values and has reason to value. This is closely related to the principle of each person as an end: if the focus lies on how particular arrangements or programs affect individuals, and it has to be assured that the interests of each person are served, the specific objectives of a program necessarily have to be defined by those affected by it. This is what the PS mentoring program aims to accomplish: participating families identify which of the poverty indicators matter most to them, as a starting point for the mentoring process. Based on these priorities, the mentors then work with the families to analyze potential causes of the problem and to identify and develop solutions. In the PS mentoring framework, the "right" solution for a given indicator might look very differently for one family compared to another.

\section{Method and Data}

The present analysis uses administrative data from over 9,100 FP microfinance clients who were randomly selected to participate in the PS program at any point between August 2015 and June 2017. New participants entered the program every month, and this paper refers to the program entry survey of each individual as "baseline" and to the subsequent surveys as "follow-up". Follow-up data from within the study period is available from around 2,600 participants.

PS data consists, for each participant, of a brief socioeconomic survey and the 50 Stoplight indicators coded as Red, Yellow, or Green. This paper aggregated the 50 Stoplight indicators using the Alkire-Foster (AF) methodology (Alkire \& Foster, 2011), an axiomatic approach to multidimensional poverty measurement whereby the number of deprivations each participant suffers is counted, and those above a defined threshold are identified as poor. The AF methodology is useful for the purpose of this paper, as it allows aggregation of multiple deprivations into a single multidimensional poverty score, thus providing a succinct metric to evaluate the program's effect. The PS itself uses a dashboard approach, and does thus not provide a summary statistic for a person's multidimensional poverty. 
This paper created a metric for overall poverty (using the Yellows as the deprivation cut-offs $z$ ) and for extreme poverty (using the Reds as the deprivation cut-offs $z$ ). In each case, the union criterion for poverty identification is used, meaning that a participant is considered "poor" if she is deprived in at least one indicator (Alkire \& Foster, 2011). This reflects the stated program objective of FP to help every family move to Green in everything. The metric uses a nested weighting scheme (all six PS dimensions have the same weight, and within each dimension each indicator has the same weight); all indicators together have a weight of 1 . The outcome variable is the individual's level of multidimensional poverty, measured through the deprivation count, i.e.the number of weighted deprivations the person experiences, $c_{i z} \cdot c_{i z}$ is defined as $c_{i z}=\Sigma_{j=1}^{d} w_{j} g_{i j}^{0}$, where $w_{j}$ is the weight of each indicator $j=1, \ldots d$, and $g_{i j z}^{0}=1$ if person $i$ falls under the deprivation cut-off $z$ in indicator $j$, and 0 otherwise (Alkire et al. 2015). Based on this deprivation count, the poverty incidence (headcount ratio) is $H=\frac{q}{n}$, calculated as the percentage of those identified as poor $(q)$ among all participants $(n)$, and the adjusted poverty headcount ratio, $M_{0}=\frac{1}{n} \sum_{i=1}^{n} c_{i z}$ as the average deprivation count among all participants.

The study uses a pipeline design. The program effect is identified by comparing the multidimensional poverty level at the baseline survey of those who just entered the program in a given time period with the multidimensional poverty level of those who did their follow-up survey in the same time period, controlling for the survey date (i.e., a general time trend), area of residence, and per capita family income. The two-year study period is divided into four study semesters: Semester 1 from August to December 2015; Semester 2 from January to June 2016; Semester 3 from July to December 2016; and Semester 4 from January to June 2017. The program effect is estimated for the pooled database as well as separately for semesters two through four (no follow-up data is available for the first study semester). Estimates are based on OLS with loan office-level fixed effects, which account for the substantial differences in economic and social conditions between the different regions of Paraguay. The model is defined as

Model 1: $c_{z}=\beta_{0}+\beta_{1}$ followup $+\beta_{2}$ time $+\beta_{3}$ income $+\beta_{4}$ rural $+\beta_{5 s}$ office s $_{s}+e$

where $c_{z}$ is the deprivation count for deprivation cut-off $z$ (extreme or overall deprivation within each indicator), followup is a dummy variable with the value 1 if the survey is a follow-up and 0 if the survey is baseline, time is the number of days since the first observation in the entire sample (August $7^{\text {th }}, 2015$ ); income is the monthly family per capita income level, in 10,000 current Paraguayan Guaraní (at the time approximately USD1.8); and rural is the residency area (which is a dummy taking the value 1 if the client lives in a rural 
area). office are the loan office-level fixed effects; the coefficients on these loan office dummies are not of interest for this study and thus not reported, but they are included to control for heterogeneities between loan offices.

Table 1 gives an overview of when clients in each baseline survey semester did their follow-up survey. The table shows that the time of program participation differs widely among clients. Furthermore, it shows significant attrition rates (participants who have not done a follow-up survey by June 30, 2017).

Table 1. Number of clients by semester of baseline and follow-up survey

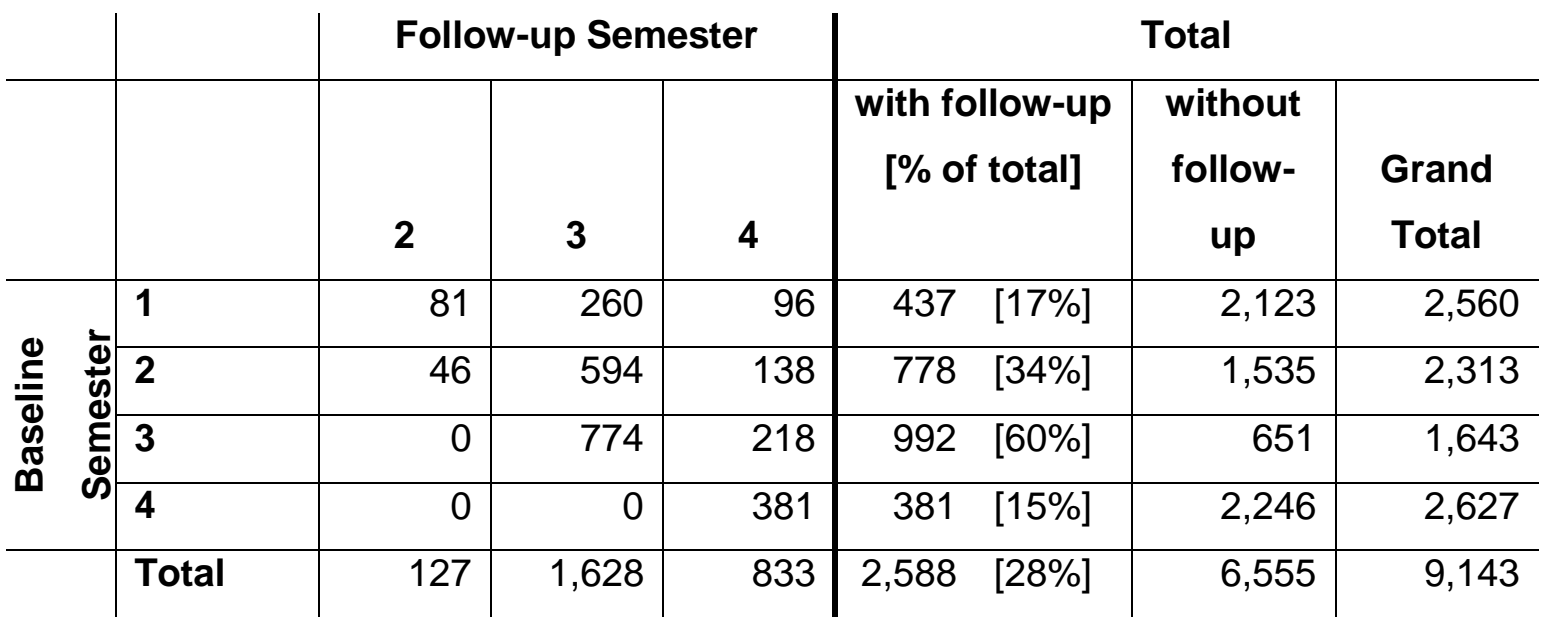

Source: self-made.

\section{Results}

Table 2 shows, for each study semester and for both overall and extreme poverty, the observed poverty headcount ratio $H$ and the adjusted headcount ratio $M_{0}$ for baseline and follow-up surveys. The data reveals a negative correlation between program participation and multidimensional poverty. In each semester and for both overall and extreme poverty, the percentage of poor survey-takers $(H)$ is larger among those doing their baseline compared to those doing a follow-up survey. These differences are statistically significant, providing a first indication for the effectiveness of the PS. A similar picture arises for the adjusted headcount ratio $\left(M_{0}\right)$. However, in this case, the difference between baseline and follow-up surveys is statistically significant only for semester two and three. 
Table 2. Multidimensional poverty incidence and adjusted incidence by survey semester and survey round (95\% confidence intervals, computed through bootstrapping, in brackets)

\begin{tabular}{|c|c|c|c|c|c|}
\hline & & \multicolumn{2}{|c|}{ Overall Poverty } & \multicolumn{2}{|c|}{ Extreme Poverty } \\
\hline Sem. & & Baseline & Follow-up & Baseline & Follow-up \\
\hline \multirow[t]{4}{*}{1} & $\mathbf{H}$ & $99.0 \%$ & & $85.6 \%$ & \\
\hline & & {$[98.5 \%-99.5 \%]$} & & [82.1\% - 89.2\%] & \\
\hline & MO & 0.219 & & 0.078 & \\
\hline & & [0.201 - 0.236] & & [0.071 - 0.084] & \\
\hline \multirow[t]{4}{*}{2} & $\mathbf{H}$ & $98.9 \%$ & $86.8 \%$ & $88.2 \%$ & $71.1 \%$ \\
\hline & & [98.1\% - 99.7\%] & [79.3\% - 94.2\%] & [85.1\%- $91.3 \%]$ & {$[61.6 \%-80.5 \%]$} \\
\hline & MO & 0.193 & 0.127 & 0.073 & 0.046 \\
\hline & & [0.182 - 0.205] & [0.098 - 0.155] & [0.066 - 0.081] & [0.036 - 0.055] \\
\hline \multirow[t]{4}{*}{3} & $\mathbf{H}$ & $99.2 \%$ & $71.3 \%$ & $77.1 \%$ & $58.4 \%$ \\
\hline & & [98.6\% - 99.8\%] & [67.1\% - 75.4\%] & {$[72.6 \%-81.7 \%]$} & {$[53.8 \%-62.9 \%]$} \\
\hline & MO & 0.162 & 0.101 & 0.056 & 0.036 \\
\hline & & {$[0.150-0.173]$} & [0.092-0.111] & [0.049 - 0.063] & [0.031-0.041] \\
\hline \multirow[t]{4}{*}{4} & $\mathbf{H}$ & $97.1 \%$ & $73.0 \%$ & $71.0 \%$ & $55.7 \%$ \\
\hline & & {$[95.5 \%-98.6 \%]$} & [67.8\% - 78.3\%] & {$[65.5 \%-76.5 \%]$} & {$[49.6 \%-61.8 \%]$} \\
\hline & MO & 0.108 & 0.087 & 0.039 & 0.032 \\
\hline & & [0.097 - 0.118] & [0.076 - 0.097] & [0.035 - 0.044] & [0.026 - 0.038] \\
\hline
\end{tabular}

Source: self-made.

Table 3 presents the results of the OLS estimates for overall and extreme poverty (Panel A and Panel B, respectively). The regressions are done first aggregating across the entire study period, and then separately for semesters two through four. The results show that in all study semesters and aggregated over the entire period, those who are doing their followup survey experience less overall multidimensional poverty (counting both Yellows or Reds, Panel A) compared to those who are newly entering the program. For extreme poverty (counting only Reds, Panel B), the same is true on the aggregate and in two study semesters. The size of the effect for the overall deprivation count is a reduction of between 0.02 and 0.05 , corresponding to a reduction of between 1 and 2.5 Yellows or Reds (given the total number of 50 indicators). For the extreme deprivation count, the reduction amounts to between 0.006 and 0.02 , corresponding to a reduction of between 0.3 and 1 Reds. 
For all models, higher income is significantly correlated with lower multidimensional poverty, while living in a rural area is only consistently associated with higher levels of extreme multidimensional poverty. Furthermore, there is a clear negative time trend: other things equal, the expected multidimensional poverty level is lower the later the survey is taken.

Table 3. OLS results

Panel A: Dependent variable: deprivation count vector for overall poverty

\begin{tabular}{|c|c|c|c|c|}
\hline & Aggregate & Semester 2 & Semester 3 & Semester 4 \\
\hline \multirow[t]{2}{*}{ Follow-up } & $-.0345^{\star \star *}$ & $-.0506^{\star * *}$ & $-.0255^{\star * *}$ & $-.02^{* *}$ \\
\hline & $(-8.68)$ & $(-5.77)$ & $(-4.24)$ & $(-3.35)$ \\
\hline \multirow[t]{2}{*}{ Date } & $-.00018^{\star \star \star}$ & 0.000063 & $-.00047^{\star \star *}$ & $-.00012^{*}$ \\
\hline & $(-10.06)$ & $(0.86)$ & $(-6.04)$ & $(-2.14)$ \\
\hline \multirow[t]{2}{*}{ Income p.c. } & $-.00056^{\star * *}$ & $-.00063^{* * *}$ & $-.00057^{* \star *}$ & $-.00035^{\star * *}$ \\
\hline & $(-12.69)$ & $(-13.17)$ & $(-9.91)$ & $(-7.96)$ \\
\hline \multirow[t]{2}{*}{ rural } & .0128 & .00941 & .0248 & $.025^{\star \star \star}$ \\
\hline & (1.99) & $(1.20)$ & (1.97) & $(4.07)$ \\
\hline \multirow[t]{2}{*}{ Intercept } & $.261^{* * *}$ & $.235^{* * *}$ & $.366^{* \star *}$ & $.193^{* * *}$ \\
\hline & (33.09) & $(12.87)$ & (12.23) & (5.77) \\
\hline $\mathrm{N}$ (total) & 1,1143 & 2,351 & 3,224 & 3,083 \\
\hline N(follow-up) & 2,373 & 122 & 1,618 & 633 \\
\hline $\mathbf{R 2}$ & .336 & .296 & .34 & .281 \\
\hline
\end{tabular}

PANEL B: Dependent variable: deprivation count vector for extreme poverty

\begin{tabular}{|c|c|c|c|c|}
\hline Follow-up & $\begin{array}{c}-.0126^{* * *} \\
(-5.82)\end{array}$ & $\begin{array}{c}-.0207^{* \star *} \\
(-3.92)\end{array}$ & $\begin{array}{c}-.00721^{*} \\
(-2.30)\end{array}$ & $\begin{array}{c}-.00641 \\
(-1.69)\end{array}$ \\
\hline Date & $\begin{array}{c}-0.000065^{\star * *} \\
(-6.16)\end{array}$ & $\begin{array}{c}-0.000041 \\
(-1.18)\end{array}$ & $\begin{array}{c}-.00019^{* * *} \\
(-5.51)\end{array}$ & $\begin{array}{c}-0.000065^{*} \\
(-2.13)\end{array}$ \\
\hline Income p.c. & $\begin{array}{c}-.00024^{\star \star \star} \\
(-10.54)\end{array}$ & $\begin{array}{c}-.00029^{* * *} \\
(-8.94)\end{array}$ & $\begin{array}{c}-.00022^{* * *} \\
(-9.02)\end{array}$ & $\begin{array}{c}-.00014^{* * *} \\
(-5.98)\end{array}$ \\
\hline rural & $\begin{array}{c}.0129^{* * *} \\
(4.12)\end{array}$ & $\begin{array}{l}.0111^{*} \\
(2.55)\end{array}$ & $\begin{array}{l}.0139^{\star} \\
(2.52)\end{array}$ & $\begin{array}{c}.0173^{* * *} \\
(4.52)\end{array}$ \\
\hline Intercept & $\begin{array}{l}.0868^{* * *} \\
(19.80)\end{array}$ & $\begin{array}{l}.0987^{* * *} \\
(10.59)\end{array}$ & $\begin{array}{l}.121^{\star \star *} \\
(8.87)\end{array}$ & $\begin{array}{c}.0732^{* * *} \\
(3.80)\end{array}$ \\
\hline N(total) & 1,1143 & 2,351 & 3,224 & 3,083 \\
\hline N(follow-up) & 2,373 & 122 & 1,618 & 633 \\
\hline $\mathbf{R 2}$ & .265 & .286 & .256 & .25 \\
\hline
\end{tabular}


Office-level fixed effects included but not reported. Standard errors clustered at office level.

t-statistics in parenthesis. * $p<0.05,{ }^{* *} p<0.01,{ }^{* * *} p<0.001$

Source: self-made.

\section{Discussion}

The results are encouraging and support the conclusion of the previous studies that participation in the PS program helps families reduce their deprivations. On average, study participants spent about six months in the program, over which time they could decrease their Reds by between 0.3 and 1, and their Yellows or Reds by between 1 and 2.5, in addition to a favorable time trend of a decreasing overall and extreme deprivation count. Note that the entire study population are microfinance clients, which might explain at least part of the overall decrease; the results suggest that participating in the PS program in addition to the microfinance program increases participants' welfare even further. Overall, the results support the notion that a poverty self-assessment and mentoring program can help people overcome poverty, as the CA would suggest. In other words, this paper provides evidence that suggests that participating in the PS, a multidimensional poverty self-assessment and mentoring intervention, might increase participants' agency and thus reduce their deprivations.

As discussed, the PS indicators measure well-being mostly on the level of functionings, or resources, and not on the level of capabilities. Therefore, the evidence brought forward in the empirical analysis does on allow to conclude that participants managed to expand their capabilities. However, as the PS program theory is in line with the CA, from the moment of reflecting on the status quo (changing frames of reference), to defining priorities for improvement (working on improving what a client values), to building of agency to act on these priorities, it seems at least possible that such a capability expansion has indeed occurred.

However, this analysis has some important limitations, most prominently the lack of a control group, which makes it harder to isolate the program effect. Furthermore, as follow-up data is available only for about $35 \%$ of program participants, systematic program attrition is a serious concern. While a robustness analysis suggests the results don't change qualitatively if the analysis is limited to those clients for whom follow-up data is available (results not reported), a potential bias from systematic attrition cannot be ruled out. Finally, the validity of our results might also suffer because the average time difference between baseline and follow-up surveys was only around 6 months. This time difference may well be too short for sustainable changes in multidimensional poverty, especially changes that are related to an increase of agency and capabilities, which tend to be long-term processes. Finally, as argued 
in the previous paragraph, based on our results a capability expansion can only be assumed, not evidenced.

\section{Conclusions}

This paper presents evidence on the question whether a multidimensional poverty selfassessment and mentoring intervention can increase participants' agency and thus reduce poverty. The theoretical part of this paper developed the PS as a Capability Application, using the CA to explore the potential of the PS intervention to increase agency and decrease deprivations, while the empirical part presented the results of a program evaluation. Both the theoretical analysis and the results of the empirical study conclude that multidimensional poverty self-assessment and integrated mentoring is a promising approach to support families on their pathway out of poverty. Specifically, the empirical evidence showed that participating in the PS program in addition to the microfinance program increases participants' welfare and reduces their deprivations.

In relation to the limitations of this paper, more research is needed to truly understand the effects of the PS on multidimensional poverty and capability expansion, and the mechanisms through which agency might be enhanced. As summarized in the discussion section, the results should be validated in further studies that include a control group, account for attrition rates, and take a longer time horizon. In addition, the analysis should be expanded to learn how various dimensions of multidimensional poverty are affected by the program, or whether the results can be replicated by using other conceptualizations of multidimensional poverty. However, it is important to note that this paper summarized a part of a larger research project that uses mixed methods to answer some of these questions. In particular, this larger project explores local notions of empowerment and the PS's perceived effect on it through participatory qualitative as well as quantitative methods; and this research started a new randomized evaluation in 2017 that not only adds a control group to better understand the program effect, but also allows to compare outcomes of different mentoring models and intensities.

In relation to possible extensions to this paper, some important open questions remain about the program with regards to the CA. Without any claim to comprehensiveness and in no particular order, these include the following. First, the pronounced objective of the PS is to help participants become Green in everything. Considering that a number of the indicators are to be located in the space of resources or functionings (as opposed to capabilities), it is not clear how to reconcile this prescribed objective with the claimed focus on agency and the areas a participant values. 
Second and related, one might argue that in many cases the PS does not promote capabilities, but specific functionings and thus specific lifestyle choices. Given the inherent difficulties in measuring "choice", it becomes a common problem of multidimensional poverty metrics based on the CA. However, the PS is not just a pure metric that needs to resort to proxy measures where the real concept of interest is not available. Rather, its indicators are developed with the explicit purpose of encouraging reflection and promoting agency. Therefore, one might argue that resorting to the space of functionings or resources, rather than capabilities, is a bigger problem for the PS than it is for other metrics.

Third, the CA emphasizes the individual as the center of development, not the groups an individual might belong to. However, the PS, while typically working with individuals, has a focus on families: According to FP, the family is the central unit of analysis, and in fact most indicators are formulated at the level of the family. FP argues that families generally share resources, and it will be impossible to eliminate the poverty of, say, the family's children without at the same time eliminating the poverty of the mother. A scholar developing an instrument strictly from the perspective of the CA would most likely not make that choice, and its implications for the interventions from the perspective of the CA deserve further scrutiny.

\section{References}

Alkire, S. (2005). Subjective Quantitative Studies of Human Agency. Social Indicators Research, 74(1), 217-260.

Alkire, S. \& Deneulin, S. (2009). Introducing the Human Development and Capability Approach. An Introduction to the Human Development and Capability Approach. London: Earthscan.

Alkire, S. \& Foster, J. (2011). Counting and multidimensional poverty measurement. Journal of Public Economics, 95, 476-487.

Alkire, S. \& Santos, M. E. (2010). Acute Multidimensional Poverty: A New Index for Developing Countries [OPHI Working Paper No. 38].

Alkire, S., Foster, J., Seth, S., Santos, M. E. \& Roche, J. M. (2015). Multidimensional Poverty Measurement and Analysis. New York: Oxford University Press.

Alsop, R., Bertelsen, M. F. \& Holland, J. (2006). Empowerment in Practice: From Analysis to Implementation. World Bank.

Appadurai, A. (2004). The Capacity to Aspire: Culture and the Terms of Recognition. In V. Rao \& M. Walton (Eds.), Culture and Public Action (pp. 59-84). Stanford, CA: Stanford Univ. Press. 
Bandiera, O., Burgess, R., Das, N., Gulesci, S., Rasul, I. \& Sulaiman, M. (2017). Labor Markets and Poverty in Village Economies. The Quarterly Journal of Economics, 132(2), 811-870.

Bandura, A. (1997). Self-efficacy: The exercise of control. New York: W H Freeman/Times Books/Henry Holt \& Co.

Banerjee, A., Duflo, E., Goldberg, N., Karlan, D., Osei, R., Parienté, W., Shapiro, J., Thuysbaert, B. \& Udry, C. (2015). A multifaceted program causes lasting progress for the very poor: Evidence from six countries. Science, 348(6236), 1260799.

Banerjee, A., Karlan, D., Osei, R. D., Trachtman, H. \& Udry, C. (2018). Unpacking a MultiFaceted Program to Build Sustainable Income for the Very Poor (No. 24271).

Beaman, L., Duflo, E., Pande, R. \& Topalova, P. (2012). Female Leadership Raises Aspirations and Educational Attainment for Girls: A Policy Experiment in India. Science, 335(6068), 582-586.

Bernard, T., Dercon, S., Orkin, K. \& Taffesse, A. S. (2014, April 21). The Future in Mind: Aspirations and Forward-Looking Behavior in Rural Ethiopia. Retrieved from http://www.worldbank.org/content/dam/Worldbank/Feature\%20Story/Africa/afrtanguy-bernard.pdf

Budzyna, L. \& Magnoni, B. (2013). Measuring the Social Impact of Fundación Paraguaya. EA Consultants.

Burt, M. (2013). The "Poverty Stoplight" Approach to Eliminating Multidimensional Poverty: Business, Civil Society, and Government Working Together in Paraguay (Innovations Case Narrative: Fundación Paraguaya). Innovations: Technology, Governance, Globalization, 8(1-2), 55-75.

Burt, M. (2014). The Poverty Stoplight: Does personalized coaching in microfinance help clients overcome poverty? [Unpublished internal document]. Asunción:

Fundación Paraguaya.

Burt, M. (2019). Who Owns Poverty? Dorset: Red Press Ltd.

Chambers, R. (1997). Whose Reality Counts?: Putting the First Last. Intermediate Technology.

Clark, D. A. (2005). Sen's capability approach and the many spaces of human well-being. Journal of Development Studies, 41(8), 1339-1368.

Conradie, I. \& Robeyns, I. (2013). Aspirations and Human Development Interventions. Journal of Human Development and Capabilities, 14(4), 559-580.

Dalton, P. S., Ghosal, S. \& Mani, A. (2016). Poverty and Aspirations Failure. The Economic Journal, 126(590), 165-188. 
Deneulin, S. \& Shahani, L. (Eds.). (2009). An Introduction to the Human Development and Capability Approach: Freedom and Agency. London; Sterling: Ottawa: Routledge.

Eby, L. T., Allen, T. D., Evans, S. C., Ng, T. \& DuBois, D. L. (2008). Does mentoring matter? A multidisciplinary meta-analysis comparing mentored and nonmentored individuals. Journal of Vocational Behavior, 72(2), 254-267.

Ervin, P. A., Ervin, L. G. de, Vega, J. R. M. \& Sacco, F. G. (2017). Multidimensional Poverty in Paraguay: Trends from 2000 to 2015. Social Indicators Research, 1-42.

Fletcher, J. K. \& Ragins, B. R. (2007). Stone Center Relational Cultural Theory: A Window on Relational Mentoring. In B. R. Ragins \& K. Kram (Eds.), The Handbook of Mentoring at Work: Theory, Research, and Practice (pp. 373-399). Los Angeles: SAGE Inc.

Freire, P. (1970). Pedagogy of the Oppressed. Continuum.

Freire, P. (1973). Education for Critical Consciousness. Continuum.

Fundación Paraguaya. (2014). Manual metodológico del Semáforo de Eliminación de Pobreza [Internal Training Document]. Asunción: Fundación Paraguaya.

Fundación Paraguaya. (2018a). Poverty Stoplight Brochure. Retrieved from Fundación Paraguaya website: https://www.povertystoplight.org/en/content

Fundación Paraguaya. (2018b). The Poverty Stoplight 3.0 Indicators. Asunción: Fundación Paraguaya.

Genicot, G. \& Ray, D. (2011). Aspirations, Inequality, Investment and Mobility. Retrieved from https://www.researchgate.net/publication/267549856

Genicot, G. \& Ray, D. (2017). Aspirations and Inequality. Econometrica, 85(2), 489-519.

Hart, C. S. (2012). Aspirations, Education \& Social Justice. Applying Sen \& Bourdieu. London: Bloomsbury Press.

Hart, C. S. (2016). How Do Aspirations Matter? Journal of Human Development and Capabilities, 17(3), 324-341.

Ibrahim, S. S. (2011). Poverty, Aspirations and Well-Being: Afraid to Aspire and Unable to Reach a Better Life - Voices from Egypt [BWPI Working Paper 141]. Manchester: Brooks World Poverty Institute.

Ibrahim, S. S. \& Alkire, S. (2007). Agency and Empowerment: A Proposal for Internationally Comparable Indicators. Oxford Development Studies, 35(4), 379-403.

Janzen, S. A., Magnan, N. P., Sharma, S. \& Thompson, W. M. (2017). Aspirations failure and formation in rural Nepal. Journal of Economic Behavior \& Organization, 139, $1-25$.

Kabeer, N. (1999). Resources, agency, achievements: Reflections on the measurement of women's empowerment. Development and Change, 30, 435-464. 
Lybbert, T. J. \& Wydick, B. (2017). Hope as Aspirations, Agency, and Pathways: Poverty Dynamics and Microfinance in Oaxaca, Mexico. In NBER Chapters.

Macours, K. \& Vakis, R. (2009). Changing Households' Investments and Aspirations Through Social Interactions: Evidence From a Randomized Transfer Program (No. 5137).

Narayan, D. (Ed.). (2005). Measuring Empowerment: Cross-Disciplinary Perspectives. Washington, D.C.: World Bank, c2005: World Bank Publications.

Nussbaum, M. C. (2000). Women and Human Development: The Capabilities Approach. Cambridge University Press.

Poveda, S. (2015). Conscientisation and Human Development: The case of digital inclusion programmes in Brazil (Ph.D. Dissertation). London: University of London.

Ray, D. (2006). Aspirations, Poverty, and Economic Change. In A. Banerjee, R. Bénabou, \& D. Mookherjee (Eds.), Understanding Poverty (pp. 409-421). New York: Oxford University Press.

Rhodes, J. E. \& DuBois, D. L. (2008). Mentoring Relationships and Programs for Youth. Current Directions in Psychological Science, 17(4), 254-258.

Robeyns, I. (2003). The Capability Approach: An Interdisciplinary Introduction. Training Course Preceding. Presented at the Third International Conference on the Capability Approach, Pavia, Italy.

Robeyns, I. (2017). Wellbeing, Freedom and Social Justice: The Capability Approach ReExamined. Cambridge: OpenBook Publishers.

Sen, A. (1992). Inequality Reexamined. Clarendon Press.

Sen, A. (1999). Development as Freedom. Anchor Books, Random House LLC.

Sen, A. (2004). Rationality and Freedom. Cambridge, Mass.: Belknap Press: An Imprint of Harvard University Press.

Sen, A. (2009). Capability: Reach and Limit. In E. Chiappero-Martinetti (Ed.), Debating Global Society. Reach and Limit of the Capability Approach (pp. 15-28). Milan: Feltrinelli.

Sheldon, T. (2017, February 7). Can the Graduation Approach Help to End Extreme Poverty? Retrieved November 29, 2019, from Yale Insights website: https://insights.som.yale.edu/insights/can-the-graduation-approach-help-to-endextreme-poverty. 